\title{
Notes on Operations Improving the Flow of Materials in a Cataloging Department:
}

\section{Using ADDIE for a Project in the Ohio State University Libraries}

\section{By Melanie McGurr}

The Cataloging Department at the Ohio State University Library continuously reviews workflow to see which areas need improvement. In 2004, the Cataloging Department began receiving complaints about the time it took to locate unprocessed materials within Technical Services. Locating these materials was difficult and time consuming, causing problems for both patrons and staff. The author reports on a project that examined the workflow of unprocessed materials in the Cataloging Department at Ohio State. Using the instructional design ADDIE model, a new workflow was designed and implemented to ensure that items could be located, processed, and delivered to patrons in a timely manner. The paper concludes with suggestions applicable to other libraries.

\section{Introduction}

$\mathrm{M}$ aintaining a flexible and effective workflow for cataloging new materials and handling problem materials that come back for recataloging or record maintenance is an ongoing challenge, especially at a large university. One of the most difficult challenges is ensuring patron access to the books being processed in a cataloging unit. The catalyst for this investigation was an increasing number of comments from patrons and staff about the time required to locate unprocessed items in the Technical Services unit. Because both order and in-process records are available to patrons and staff via the online cata$\log$, items can be requested as soon as they are received by the Acquisitions Department. If an unprocessed item was requested from Technical Services, it could take hours, if not days, to locate the item. Because this wasted the time and effort of both patrons and staff, the Cataloging Department decided to investigate the workflow of unprocessed materials to identify problem areas and to propose solutions to allow Technical
Services staff to locate, process, and deliver items to patrons in a timely manner. This paper reports the findings and results of that initiative.

\section{Background}

Cataloging for the Ohio State University Libraries (OSUL) is done in many departments, including the Monographs Department (MOD), Scholarly Resources and Integration (SRI), Cataloging (CAT), Serials and Electronic Resources (S/ER), and Special Collections Cataloging. MOD completes simple copy cataloging and most PromptCat record processing. All copy cataloging or PromptCat materials in a foreign language are forwarded to CAT, as is any cataloging copy that lacks a call number or subject headings, needs series work, or has uniform title problems. If MOD cannot complete receipts within two weeks from receipt, overflow is sent to CAT. Foreign-language materials from SRI are forwarded to CAT. CAT is also responsible for original cataloging for books in all languages, copy cataloging of books in foreign languages, much 
of the cataloging for regional campuses, and audio-visual cataloging. Items also come to the department from individuals: collection managers, preservation specialists, donors, public service professionals, and circulation personnel. Because thousands of items come through this department from many different directions, effective organization and workflow are imperative.

This project had two main objectives: identify how to make unprocessed materials in CAT easily accessible for patrons, and facilitate control of unprocessed materials within one location.

Because of the department-wide implications for the project, a careful plan was needed. Changing small parts of the workflow here and there to test theories would mean constant changes for the department. A plan that factored time for design and testing was needed to minimize unnecessary interruptions in daily workflow. The experiences of the author, including time spent as an instructional designer and years as a college instructor, factored into the decision to use the ADDIE model. ADDIE stands for analysis, design, development, implementation, and evaluation, and is the process traditionally used in instructional design. In the ADDIE model, each step has an outcome that feeds into the subsequent step, resulting in a dynamic, flexible process.

Variations of this model are used throughout the e-learning industry and in instructional design projects in educational settings, including libraries. According to Molenda, no official definition for the model exists. ${ }^{1}$ Unlike popular reorganization plans, such as Six Sigma (developed by Motorola as a process improvement technique), the ADDIE model is not copyrighted or trademarked; therefore it is an inexpensive and flexible model to use and adapt.

\section{Literature Review}

Many authors have written about reorganizing cataloging workflow, but few have dealt with specific details of problem-solving or backlogs of books. Many articles on workflow in academic libraries evaluate the flow of materials between acquisitions, copy cataloging, and original cataloging units. Ohio State recently moved the copy cataloging functions from the Cataloging Department to the Acquisitions Department. ${ }^{2}$ According to Freeborn and Mugridge, this switch in copy cataloging duties has gained popularity since the early 1990s, and they cite Ohio State as a successful example. ${ }^{3}$ A similar project is explained by Branton and Englert from the University of Southern Mississippi. ${ }^{4}$ Studies of using OCLC services and products, such as PromptCAT, to speed up the acquisitions and copy cataloging processes are discussed in articles by Coats and Kiegel at the University of Washington Libraries and Maurer and Hurst at Kent State University. ${ }^{5}$ Coats and Kiegel also discuss using Microsoft Access to run queries on books in the cataloging department to organize PromptCat records. ${ }^{6}$

The major evaluation and reorganization of cataloging and workflow at specific colleges and universities have produced useful articles. Condron describes a project at Tufts University's main library that changed the way the Cataloging Department handles workflow from top to bottom, but that also met with much opposition and uncertainty from the professionals and staff. ${ }^{7}$ Everyone in the department was affected by the changes, which included cross-training and position changes. Condron's emphasis on the challenges of change, the importance of communication, and the use of focus groups and team meetings to facilitate change are valuable.

Although some library literature addresses the eradication of backlogs, articles including information on prob- lem book backlogs are not plentiful. A few articles on eradicating backlogs are pertinent to the situation at Ohio State. Chao and King of Brigham Young University explain how they are handling a backlog in their Chinese, Japanese, and Korean collection by ensuring that all items are available for patron access through creation of a brief bibliographic record with a local call number in the catalog. ${ }^{8}$ Patrons can then locate and check out items, which are given a full record when they are returned to the library. Books are also cataloged on demand if they are requested by patrons. Kresge discusses the change in workflow at Bowdoin College, which had a similar problem to Ohio State's. ${ }^{9}$ Bowdoin, like Ohio State, had difficulties with multiple people handling one item, a small backlog, and an unacceptable lag in cataloging new receipts.

Articles dealing with process improvement in libraries were also consulted because of an interest in careful analysis and design before disrupting every day workflow. Six Sigma, an extremely popular processimprovement model in the business world, was used at the Newcastle University Library to improve their self-service. ${ }^{10}$ Two projects at Notre Dame University were of interest. ${ }^{11}$ The Electronic Reserves unit used process improvement to improve workflow functionality and the Serials unit used process improvement to construct a new workflow as they migrated from one system to another. Nozero and Vaughan's article about managing change at the University of Nevada, Las Vegas, was especially helpful in its discussion of reorganization versus process improvement. ${ }^{12}$ They describe reengineering as a radical top-down approach to a major change or crisis, while process improvement is a gradual change brought about by a team-led initiative and could involve people at all levels of the academic library hierarchy.

Little scholarly information exists 
on the use of the ADDIE model in libraries. Swanson's article details how Moraine Valley Community College used ADDIE to assist the library staff with keeping up with the curriculum at the school. ${ }^{13}$ Ohio State's problem was important, but certainly not a crisis, so reorganization was not seen as necessary. Process improvement was a more attractive avenue. Process improvement was needed for the workflow, but the model needed to be scaled down. Because of the experiences of the person assigned to the project (the author), the ADDIE model was used.

\section{Data Collection}

Data needed to be collected to measure the extent of the problem and inform the analysis phase. To achieve the two objectives of this study (easy access for patrons and improved control of unprocessed materials), a sample was collected from unprocessed materials in CAT. This sample was taken within one month-March 2004 — in CAT and focused on western language materials. Unprocessed materials housed in all workstations within the department were inventoried. The items sampled were from the regular workflow (no gift collections or retrospective projects). The books could be new, unprocessed books, or books sent to CAT for correction. The cataloging department received 942 items that were inventoried for barcodes, bibliographic records, and location codes. Information concerning the items was gathered on paper first because the items were spread throughout the department, and then transferred to an Excel spreadsheet. This information included status code, the presence of a barcode, and the presence of a bibliographic and item record. Because one objective was improved ability to find items, the status code of these items was a critical piece of information. Table 1 shows the different status codes possible for the books in the department. The status code is located in the item record and appears as a message to patrons in the online catalog. Staff often change status codes to show that an item is missing, being transferred, withdrawn, and so on.

Fixing problems and processing items during the inventory was too disruptive. Instead, a note was added to the item records with the correct status (at Technical Services), stating that the items were in CAT, the initials of the staff person inventorying the item, and the date. Those items with the wrong status were corrected and the note, initials, and date added to the item record. The books not in the catalog at all were given high priority.

\section{Findings and Analysis}

After the data were collected, the next step was analysis. Table 2 presents totals for types of problems found in the initial inventory. An item could have more than one problem (for example, a book that does not have a barcode but is in the catalog could also be listed as missing). A total of 989 problems were identified in 942 items. The inventory showed that most items in the sample were listed as available for checkout even though the item remained in CAT (table 2). Incorrect status codes were causing serious problems. The disturbing fact was that these codes were found on items in the department that were not readily available for patron access. Of the items inventoried, 397 items were coded as available: in other words, as being on the shelf and ready for patrons to check out. Of these items, 225 items were not in the catalog at all, which meant they did not exist for patrons. The 308 items without barcodes could be easily fixed, but through a time-consuming process. The 49 bibliographic records without item records were also problematic because a bibliographic record with no

\begin{tabular}{ll}
\hline Table 1. Possible status codes \\
\hline Code & Explanation \\
) & OhioLINK requested \\
$\mathrm{d}$ & Ask at desk \\
$\mathrm{H}$ & Use in library \\
$\mathrm{J}$ & Not available \\
$\mathrm{k}$ & Being transferred \\
$\mathrm{m}$ & Temporarily missing in order to \\
$\mathrm{p}$ & create search file \\
$\mathrm{s}$ & In process \\
$\mathrm{w}$ & Missing \\
$\mathrm{a}$ & Withdrawn \\
- & At Technical Services \\
\hline
\end{tabular}

item record is confusing for patrons. A bibliographic record with no item record attached shows patrons information about an item, but does not display location or availability. Item records at OSUL contain not only information on location and availability, but also contain the codes for rules of circulation (for example, if the item cannot leave the library or can only circulate as a reserve item) and other codes that help patrons and circulation understand how the item is to be handled.

M (missing) status code problems were extremely serious because almost all of these instances meant that patrons and staff were not able to locate an item and staff had changed the status code to missing. This could mean another copy was ordered or patrons went without an item that was actually waiting for processing in CAT. Only 113 of 942 items (12 percent) were labeled correctly as being in Technical Services.

The main problem was that books were coming to the department by many channels. The status of the items was not being consistently changed by the department sending the items to CAT or by anyone in CAT. The public displays for a large number of books 
Table 2. Types of problems identified in the March 2004 inventory

(sample = 942 items: 113 correct, 989 problems)

\section{Status Codes}

Listed as available for checkout

M (missing)

No barcode

Not in catalog

No item record

Purchase being considered

Total

Note: Some items had more than one problem.

(397 in this sample) that arrived at CAT continued to indicate that they were available. This status was not changed when the books arrived in CAT. An item may wait for attention in Technical Services for a while, depending on the complexity of the problem and the workload of the department. Because so many people send items to Cataloging, they could not be depended on to remember to change the status of items and the solution needed to be found within Cataloging. The entire process needed to be centralized and effectively organized.

\section{Design and Development}

The design and development phase of the ADDIE model began at this stage, following analysis. The proposed solution was twofold: a new staff member was hired to be responsible for ensuring the items displayed as being at Technical Services, and all items needed to be prioritized. A new workflow was designed in which a staff member was placed in charge of receiving materials that arrive at the department. Any item coming into the department would go through this single person to ensure that it would be checked out to Technical Services, dated, and initialed. New "unpro-
No. of Problems

397

10

308

225

49

0

989
$\%$ of Total Problems

40.1

1.0

31.1

22.8

5.0

0

100 cessed" location codes were created to show that items were in Technical Services awaiting processing so they could be sent to a specific location. For example, a book targeted for the Main Library would have a location code assigned to unprocessed books intended for Main Library. If an item did not already have an OCLC record from the time of order, then a record would be brought in from OCLC or a brief record created so that patrons could see information about an item and where it was located even before it was processed.

These details in the record indicate when the book arrived, and where it would go in the Technical Services Department. The new staff person also would be the contact person for locations and patrons trying to locate a particular item or items. The new location codes and dates help the staff person to track down where the book should be located in the Department. Although this requires an extra person handling each item, it also means that this staff person can facilitate a patron's ability to locate the item by updating the item record to keep the location current. It also means that the new staff person would be keeping statistics on the books coming into the department. This staff person can also distribute new receipts to the appropriate staff for processing.
Secondly, the problem items needed to be prioritized. The decision was made to assign a high-priority item a colorful streamer. For example, a purple streamer would be placed in all books that are not in the catalog. Anyone looking at a large amount of items could quickly see which need to be addressed first. The date received also would be recorded on the streamer. A person trying to decide which item to process first can easily see that a high-priority item that came to the department a few months ago has precedence over a high-priority item that arrived yesterday.

Third, the system of assigning problematic items to specific individuals with expertise was not working. These items sometimes would sit on a book cart or on someone's desk for a long time. So everyone in the department can see what needs to be done, the unit needed a "needs work" area where anyone who has the time can tackle high-priority items first, then work down the line. If a certain series of items are in need of special care, (for example, a large authority control problem), then they can be labeled to wait for the librarian who handles authority control. If an item is in a foreign language, then it will be labeled to wait for the person or persons who can catalog in that language.

Finally, statistics needed to be kept on every item that arrives in Cataloging. This can be a simple hash-mark system or an automated approach, such as an Access database. In the case of Ohio State, an Excel spreadsheet is used to keep track of what arrives at the Department, which particular cataloger it goes to, and how many items a specific person does a month. Another option for libraries is to enter information (such as the arrival date or the location code) into an Access database, and a query can be done at a later date to see if a certain book was (or group of books were) still in the department. For example, the staff person in charge of changing 
the item records also can run queries every month to see which items sent to the department six months ago are still waiting for work. A new workflow was developed that encompassed all of these solutions.

\section{Implementation}

In the implementation (the $I$ in ADDIE) phase, the recommendations for a new workflow were put in place. The implementation stage was longer than expected because funding for a new hire needed to be approved, as well as new location codes approved and created. A new staff member was hired and trained to implement the changes for the new workflow. Training was an extensive process because of the variety of duties expected of the new person, including tracking and distributing incoming new materials, gathering monthly statistics, and communicating with the numerous library locations on campus and regional campuses of Ohio State.

The new person needed to be familiar with OCLC's Connexion to search for and export records into OSUL's local integrated library system, Innovative Interfaces' Millennium. Training in Millennium was also important because this position required knowledge of editing records and status codes, and creating lists of Boolean searches. For example, the Architecture Library on campus might need to know what books destined for their library held the status of unprocessed before a collection manager ordered new books. A Boolean search for the status code "arcb" (architecture unprocessed) could be completed and shared. Because of the demands of this position, the staff person must be flexible, organized, and friendly. Hiring an approachable person was especially important since this member of CAT had more contact with patrons and other staff and faculty throughout the library, and, for many people, repre- sented Technical Services as a whole to the rest of the University.

\section{Evaluation}

After two years of implementing and working with a new workflow, some problems were still arising, most notably the inability to find some items when they were requested from other departments at OSUL or by patrons. The final step in the ADDIE model is evaluation. In April 2006 (as part of the Evaluation phase), the department reevaluated the workflow to see if the recommendations were being followed and if the system was working smoothly. Although the criteria were the same for the second sample, this phase used a smaller data set to evaluate a typical day in the department. A sample of 250 books was randomly inventoried from all work areas. This inventory was done on a Saturday so as not to interrupt work with such a quick inventory. All items were evaluated for a bibliographic record. Items records were also checked to ensure that the proper status code was listed, the staff note was present, and a barcode was inserted. Books that adhered to the new system were identified, along with those books that did not include all the components, that is, bibliographic record, location code, staff note, and barcode, or had incorrect information. Again, the characteristics were recorded on paper and transferred to an Excel database.

Table 3 displays the results of the inventory. It showed that 152 books (60.8 percent) had been correctly handled, meaning they had a short or full bibliographic record, the correct status and location code, a staff note, and a barcode. This was a great improvement over the original inventory in which only 12 percent were correct; see table 4 for a comparison. Of the inventory, 112 books (44.8 percent) still had problems, mostly from having no item record, barcode, or record in the catalog. A few books had been waiting for attention for so long that the original short bibliographic record assigned to them was deleted.

Problems involving incorrect location codes were minimal. No items were listed as available for checkout when they were not and no items were listed as missing. One interesting problem involved the items with order records stating that this purchase was being considered for the library. The purchase was approved, ordered, and processed, but was not reflected in the item record. A patron might not have known that these books were now available for request. During the inventory, all records were corrected to display the correct information to the patron.

The original objectives have been met for the most part, and requests for materials by staff or patrons are much less problematic now that unprocessed items are easy to locate. Some problems still exist, usually because items have become separated from the original workflow or were held back for special attention because they are complex in some way. These problems are minimal compared to the first sample and can be addressed quickly.

The number of items that are correctly reflected in the online catalog is encouraging. Now if a patron or staff member needs a certain item, locating the item is much easier because the catalog record shows where the item is and where it is destined to go after processing. Also, the original inventory prompted most people to create a special problem area in their workspace so where to place items for the attention of specific staff in the department was clear, thus decreasing the chances of an item becoming misplaced.

\section{Implications for Other Libraries}

Cataloging departments should be vigilant in initiating changes in workflow 
Table 3. Types of problems identified in the April 2006 sample

$\begin{array}{lcc}\begin{array}{l}\text { (sample }=\mathbf{2 5 0} \text { items: } \mathbf{1 5 2} \text { correct, } \mathbf{1 1 2} \text { problems) } \\ \text { Status Codes }\end{array} & \text { No. of Problems } & \text { \% of Total Problems } \\ \text { Listed as available for checkout } & 0 & 0 \\ \text { M (missing) } & 0 & 0 \\ \text { No barcode } & 46 & 41.0 \\ \text { Not in catalog } & 15 & 13.4 \\ \text { No item record } & 27 & 24.1 \\ \text { Purchase being considered } & 24 & 21.4 \\ \text { Total } & 112 & 99.9\end{array}$

Notes: Some items had more than one problem. Percentage does not equal 100 because of rounding.

Table 4. Comparison of findings before and after process improvement March 2004 April 2006

\begin{tabular}{lllll} 
Number in sample & 942 & & 250 & \\
\% with no errors & 12.0 & & 60.8 & \\
No. of errors by type & $N=989$ & & No. & \% \\
& No. & \% & 0.0 & 0.0 \\
Listed as available for checkout & 397 & 40.1 & 0.0 & 0.0 \\
M (missing) & 10 & 1.0 & 46 & 41.0 \\
No barcode & 308 & 31.1 & 15 & 13.4 \\
Not in catalog & 225 & 22.8 & 27 & 24.1 \\
No item record & 49 & 5.0 & 24 & 21.4 \\
Purchase being considered & 0.0 & 0.0 & & \\
\hline
\end{tabular}

Notes: Some items had more than one error. Percentage in last column does not equal 100 percent because of rounding

that will increase the pace of processing items. Workflow issues should always be a top priority. A department should not wait until a crisis is at hand to make a change. The ADDIE model is one option for process improvement projects. Evaluating workflow and making adjustments, large and small, is a key factor in a successful department. The first step is to analyze the problem at hand. Is there a problem with incoming items? Are patrons or faculty complaining about slow cataloging or lost items? Take the time to investigate the crux of the problem before rushing in with possible solutions. The problem at Ohio State was straightforward, so that assisted in the goal for the new workflow being clear cut.

After analysis, carefully design a new workflow. Do research to discover what other libraries have done and ask the people who do the work everyday what might assist them in solving the problem. The design phase is a chance to work things out on paper before implementing a new program, so do not rush this phase. This is also a good time to brainstorm new ideas for solving problems. For example, during this phase at Ohio State, the idea of a new staff position was discussed.

Development of a new workflow may not be easy, depending on the enormity of the project. This is the chance to put a design into action. Of course, the design may not work. The project may become stalled at this stage, but going back to the design stage at this point is not failure. Going back one step may save many problems in the future. Libraries may chose to do a small sample at this point to see how the new workflow will work, and how disruptive it might be. For instance, a member of the department could begin working with the new workflow as a test during the development phase.

Implementation is the next step. Not all members of a department will be excited about a new workflow. In the case of Ohio State, the new staff member is responsible for the majority of new steps in the workflow, which helped make the change a success. Members of the department are still receiving materials and required to keep monthly statistics, but now the materials are distributed by the new staff person and the monthly statistics are also collected by the staff person.

The last step is evaluation. The choice of when to do an evaluation on the new workflow is dependent on the situation in a particular department. Ohio State's evaluation was conducted two years after the initial data were collected. This was due to a number of factors (including personnel issues), but the initial goal was to let the department have plenty of time to get used to the new workflow. A staff person had to be hired and trained, new location codes approved, the new workflow implemented, and any small problems solved.

Although Ohio State's evaluation is positive, libraries also must be prepared for a more complicated result. One of the most useful things about the ADDIE model is the ability to go back to former steps if needed. If the new workflow does not work, moving back to the design or development stage may help the process, or, if the initial problem is not fully investigated, going back to the analysis stage may be necessary. 


\section{References}

1. Michael Molenda, "In Search of the Elusive ADDIE Model," Performance Improvement 42, no. 5 (May/June 2003): 34-36.

2. MagdaEl-Sherbini, “CopyCataloguers and Their Changing Roles at the Ohio State University Library: A Case Study," Library Management 22, no. 1/2 (2001): 80-86.

3. Robert B. Freeborn and Rebecca L. Mugridge, "The Reorganization of Monographic Cataloging Process at Penn State University Libraries," Library Collections, Acquisitions, \& Technical Services 26, no. 1 (Spring 2002): 35-45.

4. Ann Branton and Tracy Englert, "Mandate for Change: Merging Acquisitions and Cataloging Functions into a Single Workflow," Library Collections, Acquisitions, \& Technical Services 26, no. 4 (Winter 2002): 345-54.

5. Jacqueline Coats and Joseph Kiegel, "Automating the Nexus of Book
Selection, Acquisitions, and Rapid CopyCataloging," Library Collections, Acquisitions, \& Technical Services 27, no.1 (Spring 2003): 33-44: 5. Margaret Beecher Maurer and Michele L. Hurst, "Library-Vendor Collaboration for Re-Engineering Workflow: The Kent State Experience," Library Collections, Acquisitions, \& Technical Services 27, no. 2 (Summer 2003): 155-64.

6. Coats and Kiegel, "Automating the Nexus of Book Selection.”

7. Lyn Condron, "Management by Action: How We're Embracing New Cataloging Works at Tufts," Cataloging \& Classification Quarterly 32, no. 2 (2001): 127-51.

8. Ermina Choa and Gail King, "Bringing a Backlog under Control: How We Did It at BYU," Journal of East Asian Libraries 134 (Oct. 2004): 26-28.

9. Lynda S. Kresge, "Anatomy of Workflow Redesign,” Technicalities 17, no. 6 (June 1997): 1, 4-5.

10. Susan Kumi and John Morrow, "Improving Self Service the Six Sigma
Way at Newcastle University Library," Electronic Library \& Information Systems 40, no. 2 (2006): 123-36.

11. Steve Oberg, "Serials Workflow Adaptation and the New ILS: A Case for Continuous Process Improvement," Serials Review 28, no. 4 (2002): 298-315; Cameron K. Tuai, "Implementing Process Improvement into Electronic Reserves: A Case Study," Journal of Interlibrary Loan, Document Delivery \& Electronic Reserve 16, no. 4 (2006): 113-24.

12. Victoria A. Nozero and Jason Vaughan, "Utilization of Process Improvement to Manage Change in an Academic Library," Journal of Academic Librarianship 26, no. 6 (2000): 41621.

13. Troy A. Swanson. "ADDlE in the Library: Building a Model for the Information Age Library." Community \& Junior College Libraries 13, no. 2 (2005): 51-61. 